\title{
Opening of $\mathbf{K}_{\mathrm{ATP}}$ Channel Regulates Tonic Currents From Pyramidal Neurons in Rat Brain
}

\author{
Zhongxia Li, Jiangping Wang, Huimin Yu, Kewen Jiang
}

\begin{abstract}
Background: ATP-sensitive $\mathrm{K}^{+}\left(\mathrm{K}_{\mathrm{ATP}}\right)$ channels couple metabolic state to cellular excitability. Activation of neuronal and astrocytic mitochondrial $\mathrm{K}_{\mathrm{ATP}}\left(\right.$ mitoK $\left._{\mathrm{ATP}}\right)$ channels regulates a variety of neuronal functions. However, less is known about the impact of mitoK $_{\mathrm{ATP}}$ on tonic $\gamma$-aminobutyric acid (GABA) inhibition. Tonic GABA inhibition is mediated by the binding of ambient GABA on extrasynaptic GABA A-type receptors $\left(\mathrm{GABA}_{\mathrm{A}} \mathrm{Rs}\right)$ and is involved in regulating neuronal excitability. Methods: We determined the impact of activation of $\mathrm{K}_{\mathrm{ATP}}$ channels with diazoxide (DIZ) on tonic inhibition and recorded tonic current from rat cortical layer 5 pyramidal cells by patch-clamp recordings. Results: We found that neonatal tonic current increased with an increase in GABA concentration, which was partially mediated by the GABA A-type receptor $\left(\mathrm{GABA}_{\mathrm{A}} \mathrm{R}\right) \alpha 5$, and likely the $\delta$ subunits. Activation of $\mathrm{K}_{\mathrm{ATP}}$ channels resulted in decreased tonic current in newborns, but there was increased tonic current during the second postnatal week. Conclusions: These findings suggest that activation of $\mathrm{K}_{\mathrm{ATP}}$ channels with DIZ regulates GABAergic transmission in neocortical pyramidal cells during development.
\end{abstract}

RÉSUMÉ: L'ouverture des canaux $\mathbf{K}_{\text {(atp) }}$ permet de réguler les courants toniques des cellules pyramidales de rats. Contexte: Les canaux potassiques sensibles à l'ATP ou $\mathrm{K}_{(\text {atp })}$ sont associés à un état métabolique produisant l'excitabilité des cellules. L'activation des canaux neuronaux et des canaux astrocytaires mitochondriaux $\mathrm{K}_{\text {(atp) }}$ régule ainsi un éventail de fonctions neuronales. Cela dit, on en sait moins quant à l'impact de ces canaux sur l'acide $\gamma$-aminobutyrique (GABA), neurotransmetteur inhibiteur. L'inhibition tonique du GABA s'effectue en reliant le GABA extracellulaire aux récepteurs extra-synaptiques GABA-A ; cette inhibition est aussi impliquée dans la régulation de l'excitabilité neuronale. Méthodes: C'est au moyen du diazoxide que nous avons déterminé l'impact de l'activation des canaux $\mathrm{K}_{\text {(atp) }}$ sur l'inhibition tonique. À l'aide de la technique électro-physiologique du patch clamp, nous avons enregistré le courant tonique observé dans les cellules pyramidales (cinquième couche corticale) de rats. Résultats: Nous avons constaté que le courant tonique à la naissance s'est accru avec l'augmentation de la concentration de GABA, lequel fut en partie transmis par le récepteur GABA-A (sous-unités alpha 5 et probablement sous-unités $\delta$ ). Le fait d'activer les canaux $\mathrm{K}_{(\text {atp) }}$ a eu pour effet de diminuer le courant tonique chez des rats nouveau-nés. On a toutefois pu observer une augmentation de ce même courant au cours de la deuxième semaine de vie de ces rongeurs. Conclusions: Ces résultats suggèrent que l'activation des canaux $\mathrm{K}_{(\text {atp) }}$ au moyen du diazoxide permet, chez des jeunes rats, de réguler la transmission du GABA au cours du développement de leurs cellules pyramidales.

Keywords: Tonic current, mitochondrial ATP-sensitive $\mathrm{K}^{+}$channel, cortical layer 5, brain development, GABA A-type receptor doi:10.1017/cjn.2016.455

Can J Neurol Sci. 2017; 44: 718-725

\section{INTRODUCTION}

ATP-sensitive $\mathrm{K}^{+}\left(\mathrm{K}_{\mathrm{ATP}}\right)$ channels are located in various parts of the cell, including the surface of the plasmalemma $\left(\mathrm{sK}_{\mathrm{ATP}}\right)$ and mitochondrial membrane $\left(\right.$ mitoK $\left._{\mathrm{ATP}}\right) .{ }^{1} \mathrm{~K}_{\mathrm{ATP}}$ channels serve as metabolic sensors by providing a link between intracellular metabolic status and cellular excitability, ${ }^{2}$ and thereby participate in a variety of physiological functions. Activation of $\mathrm{K}_{\mathrm{ATP}}$ channels with diazoxide can modulate neuronal excitability, regulate neurotransmitter release, and protect neurons from hypoxic/ischemic injury. ${ }^{3-5}$ MitoK $_{\mathrm{ATP}}$ channels are widely distributed in the brain; there are 6-7 times more mitoK $_{\mathrm{ATP}}$ channels per gram of mitochondria in cerebral cortex than in other organs (e.g., liver and heart muscle). ${ }^{1}$ Because the brain is rich in mitoK ${ }_{\mathrm{ATP}}$ channels and diazoxide (DIZ) is considered to be a specific mito$\mathrm{K}_{\mathrm{ATP}}$ channel opener, ${ }^{6}$ we deduced that mitoK $_{\mathrm{ATP}}$ channels play a significant role in regulating neurotransmitter release and neuronal excitability. Indeed, it is our opinion that mitoK $\mathrm{ATP}_{\mathrm{AT}}$ channel function may be connected to $\mathrm{GABA}_{\mathrm{A}}$ Rs function or tonic currents.

Gamma-aminobutyric acid (GABA) is a primary inhibitory neurotransmitter in the central nervous system. Low concentrations of GABA in the extracellular space activate extra- or

From the Department of Pediatrics, Wuzhou Workers' Hospital, Wanxiu District, Wuzhou, Guangxi Zhuang Autonomous Region, China; Department of Neurology, The Children's Hospital, Zhejiang University School of Medicine, Hangzhou, China; Department of Rehabilitation, The Children's Hospital, Zhejiang University School of Medicine, Hangzhou, China; Department of Neonatology, The Children's Hospital, Zhejiang University School of Medicine, Hangzhou, China; Laboratory Department, The Children's Hospital, Zhejiang University School of Medicine, Hangzhou, China Received March 18, 2016. Final Revisions Submitted November 28, 2016; Date of ACCEPTANCE DeCEMBER 3, 2016

Correspondence to: Kewen Jiang, Department of Neurology, The Children's Hospital, Zhejiang University School of Medicine, 3333 Binsheng Road, Hangzhou, 310003, China. Email: jiangkw_zju@163.com. 
peri-synaptic $\mathrm{GABA}_{\mathrm{A}} \mathrm{Rs}$ to generate persistent tonic inhibition. Tonic inhibition is involved in maintaining an inhibitory tone, ${ }^{7}$ thus reducing the probability of action-potential firing. ${ }^{8}$ Changes in neuronal excitability are associated with schizophrenia, epilepsy, and Parkinson's disease. ${ }^{9}$ Extrasynaptic GABA $_{\mathrm{A}}$ Rs are important elements of tonic currents. Gamma-5- and $\delta$-subunitcontaining $\mathrm{GABA}_{\mathrm{A}} \mathrm{Rs}$ are primarily distributed in cortical layer $5 .^{10}$ The neurons of layer 5 are for the most part large pyramidal cells with complex dendrites and contact with other neurons, where information undergoes sophisticated processing. ${ }^{11}$

In this study, we addressed the characteristic of tonic currents with development from cortical layer 5 pyramidal neurons in the developing rat brain and determined whether or not activation of $\mathrm{K}_{\mathrm{ATP}}$ channels with DIZ regulates this developmental rule, whether or not the $\alpha 5 / \delta$-subunit-containing $\mathrm{GABA}_{\mathrm{A}}$ Rs participate in mediating the tonic currents, and if activation of $\mathrm{K}_{\mathrm{ATP}}$ channels with DIZ exerts a modulating effect on the tonic currents with intervention of $\mathrm{GABA}_{\mathrm{A}} \mathrm{R}$. Our results are expected to provide deeper insights into the regulatory functions played by DIZ in cellular excitability and the potential role of mitoK $\mathrm{K}_{\mathrm{ATP}}$ channels as a novel therapeutic target for neuropsychiatric disorders related to GABAergic system dysfunction in the developing brain.

\section{Materials AND Methods}

\section{Ethics Statement}

Our study was approved by the Ethical Committee of Animal Experiments at Zhejiang University School of Medicine, and all animal procedures complied with the guidelines of that committee. Our methods were carried out in accordance with the approved guidelines.

\section{Preparation of Brain Slices}

Male and female Sprague-Dawley rats were provided by the Experimental Animal Center of Zhejiang Province. The day of birth was considered as postnatal day $1(\mathrm{P} 1)$. Rat pups were assigned to one of three or two postnatal age groups for experiments: P2-4, P78, and P30-34 groups; or P2-4 and P7-11 groups. For fresh brain slice preparation, rats were deeply anaesthetized with $10 \%$ chloral hydrate $(380 \mathrm{mg} / \mathrm{kg})$ by intraperitoneal injection and decapitated. The brain was rapidly removed and submerged in ice-cold and oxygenated $\left(95 \% \mathrm{O}_{2}, 5 \% \mathrm{CO}_{2}\right)$ high-sucrose artificial cerebrospinal fluid (aCSF) (in $\mathrm{mM}$ ): 150 sucrose, $50 \mathrm{NaCl}, 25 \mathrm{NaHCO}_{3}$, 10 dextrose, $2.5 \mathrm{KCl}, 1 \mathrm{Na}_{2} \mathrm{HPO} 4.1 \mathrm{H}_{2} \mathrm{O}, 0.5 \mathrm{CaCl}_{2}$, and $7 \mathrm{MgCl}_{2}$; and then $300-\mu \mathrm{m}$ thick coronal slices were prepared with a vibratome (Leica VT1000, Wetzlar, Germany). Slices were transferred to a nylon holder basket (AutoMate Scientific, Berkeley, California) immersed in carbogen-bubbled aCSF containing (in $\mathrm{mM}$ ): $126 \mathrm{NaCl}, 2.5 \mathrm{KCl}, 1.25 \mathrm{NaH}_{2} \mathrm{PO}_{4}, 2 \mathrm{MgSO}_{4} .7 \mathrm{H}_{2} \mathrm{O}, 26 \mathrm{NaHCO}_{3}$, 10 dextrose, and $2 \mathrm{CaCl}_{2}$ at $35-37^{\circ} \mathrm{C}$ for $\sim 60 \mathrm{~min}$. This was followed by incubation at $22^{\circ} \mathrm{C}$ for $\sim 60 \mathrm{~min}$. All solutions were saturated with $95 \% \mathrm{O}_{2} / 5 \% \mathrm{CO}_{2}$.

\section{Electrophysiology}

The slices were transferred into a submersion-type recording chamber and superfused with oxygenated standard solution $\left(32-33^{\circ} \mathrm{C}, 2-3 \mathrm{ml} / \mathrm{min}\right)$ and anchored with platinum wires on the bottom of the recording chamber. All recordings were obtained from layer 5 pyramidal cells visually identified using an infrared-sensitive
CCD camera with a $63 \times$ water-immersion lens (Zeiss, Examiner A1, Oberkochen, Germany). Whole-cell patch-clamp recordings were carried out using a MultiClamp 700B amplifier controlled by pCLAMP 10 acquisition software (Molecular Devices, Sunnyvale, California). Currents were filtered at $1 \mathrm{kHz}$ and sampled at $5 \mathrm{kHz}$ using a Digidata 1440A (Molecular Devices). The recording pipettes were fabricated from borosilicate capillaries (OD: $1.5 \mathrm{~mm}$; Warner Instruments, Hamden, Connecticut) using a Flaming/Brown micropipette puller (Model P-97; Sutter Instruments, Novato, California). We only performed whole-cell recordings if the initial seal resistance was $\geq 2$ GS. For whole-cell recordings of tonic currents in the presence of exogenous GABA, patch electrodes (3-7 M $\Omega$ ) were filled with $\mathrm{KCl}$-based intracellular solution (in $\mathrm{mM}$ ): $40 \mathrm{~K}$-gluconate, $100 \mathrm{KCl}, 2 \mathrm{NaCl}, 10 \mathrm{HEPES}, 4 \mathrm{EGTA}, 4 \mathrm{MgATP}$, and $0.3 \mathrm{Na}_{2} \mathrm{GTP}$. For the voltage-clamp recordings, pyramidal neurons were held at $-65 \mathrm{mV}$ and bathed with $3 \mathrm{mM}$ kynurenic acid (Tocris Bioscience, Avonmouth, Bristol, UK) to block glutamate receptors. Series resistance was measured after each recording, and data were discarded if the resistance changed by more than $20 \%$ or if the series resistance was $>10 \mathrm{M} \Omega$. The tonic $\mathrm{GABA}_{\mathrm{A}} \mathrm{R}$-mediated current was defined as the current blocked by SR95531 and measured as described. ${ }^{12}$ To record tonic currents in the presence of exogenous GABA, slices were bath-perfused in GABA $(5 \mu \mathrm{M}$; Sigma, St. Louis, Missouri) for 1-3 min followed by SR95531 (gabazine-selective specificity $\mathrm{GABA}_{\mathrm{A}} \mathrm{Rs}$ inhibitors, $100 \mu \mathrm{M}$; Tocris) to block $\mathrm{GABA}_{\mathrm{A}} \mathrm{Rs}$. The $\mathrm{GABA}_{\mathrm{A}} \mathrm{R} \alpha 5$-subunit-selective inverse agonist L655708 (200 nM; Sigma) and $\delta$-preferring agonist THIP $(1 \mu \mathrm{M} \text {; Sigma })^{12}$ were bath-applied following 1-2 min of $5 \mu \mathrm{M}$ GABA, and followed by $100 \mu \mathrm{M}$ SR95531. Slices were exposed to DIZ (100 $\mu \mathrm{M}$; Sigma) and 5-hydroxydecanoate (5-HD; $100 \mu \mathrm{M}$; Sigma) for 3-5 min followed by SR95531. All perfused solutions were heated to $32-35^{\circ} \mathrm{C}$ by an in-line heater (Warner Instruments).

\section{Data Analysis}

To calculate statistical significance, we employed unpaired $t$ tests and one- or two-way ANOVAs, depending on which test was appropriate for the dataset. The specific test used is noted in the text. Data are depicted as mean \pm standard error of mean (SEM). Experimental values were considered significant if $p<0.05$.

\section{Results}

\section{Tonic Current Decreases Dramatically with Postnatal Development}

Figure 1 shows that the tonic currents markedly and rapidly decreased with development (Figure 1A,B). They decreased by $78.96 \%$ at $\mathrm{P} 7-8$ and by $85.67 \%$ at $\mathrm{P} 30-34$, respectively, which differed significantly at P2-4 $(p<0.001)$; however, no significant difference was detected between P7-8 and P30-34 ( $p>0.05$; Figure 1B). The resting membrane potential (RMP) increased with postnatal development. The level at P30-34 was significantly greater than that at $\mathrm{P} 2-4(p<0.05)$ (see Figure 1C). However, the input resistance was not significantly altered with postnatal development (see Figure 1D).

\section{Opposing Effects of $\mathrm{K}_{\mathrm{ATP}}$ Channel Opening on Tonic Currents at P2-4 versus P7-8 in the Presence of Exogenous GABA}

Figure 2 shows that, compared to controls (see Figure 1), DIZ, a specific mitoK $\mathrm{ATP}_{\mathrm{AT}}$ channel opener, inhibited the tonic 


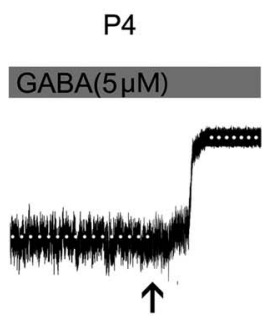

C

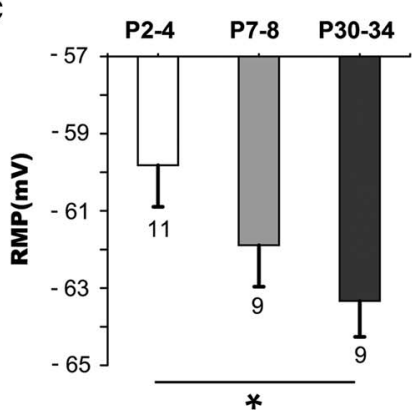

P8
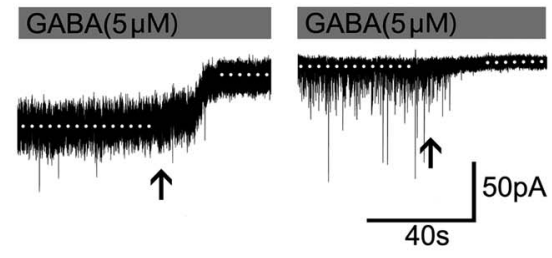

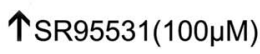

B

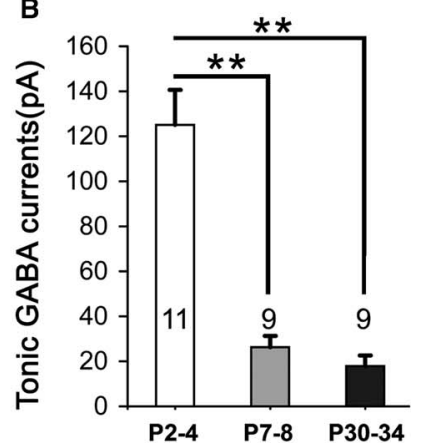

Figure 1: Tonic currents decrease dramatically with postnatal development. (A) Representative recording traces of the tonic currents from neocortical layer 5 pyramidal cells at P4, P8, and P34 with 5- $\mu M$ GABA. (B) Bar graph shows the tonic currents recorded from neocortical layer 5 pyramidal cells at P2-4, P7-8, and P30-34. The tonic currents were robust in newborns and then decreased dramatically by the second postnatal week. The resting membrane potential (RMP) increased with postnatal development. The level at $P 30-34$ is significantly greater than that at P2-4 $(p<0.05)$ (see Figure $1 C)$. However, the input resistance is not significantly altered with postnatal development (see Figure 1D). One-way ANOVA and least significant difference (LSD) post-hoc test. ${ }^{* * *} p<0.001$. Mean \pm SEM. Recordings were performed using KCl-based intracellular solution; Values within or above bars are the number of cells for the respective age group, as in Figures 2-5.

currents at P2-4 and significantly enhanced the tonic currents at both P7-8 and P30-34 (one-way ANOVA, $p<0.05$ ) (Figure 2A, C). Lastly, the magnitude of calculated tonic current after adding DIZ to the aCSF was similar. Therefore, there was no significant effect among the three age groups administered DIZ (one-way ANOVA, least significant difference [LSD] post-hoc test, $p>0.05$ ). However, we did not detect an opposite effect on the tonic currents with $5-\mathrm{HD}$, a specific mitoK $\mathrm{K}_{\mathrm{ATP}}$ channel inhibitor, as treatment with 5-HD did not significantly alter tonic currents in any of the three age groups (Figure 2B,C). Furthermore, the baseline changes $\left(\Delta I_{\text {hold }}\right)$ caused by DIZ affect the magnitude of the final tonic currents, and we found that DIZ resulted in a decrease of $59.08 \pm 7.36 \mathrm{pA}$ at $\mathrm{P} 2-4$, and increases of $49.14 \pm 3.25 \mathrm{pA}$ at $\mathrm{P} 7-8$ and $43.46 \pm 3.89 \mathrm{pA}$ at P30-34, respectively (Figure 2A,D). However, GABA resulted in decreases of $117.16 \pm 10.73 \mathrm{pA}$ at $\mathrm{P} 2-4$, $94.84 \pm 18.65 \mathrm{pA}$ at $\mathrm{P} 7-8$, and $78.57 \pm 12.18 \mathrm{pA}$ at $\mathrm{P} 30-34$, respectively (Figure 2E).

\section{Opposing Effects of $\mathrm{K}_{\mathrm{ATP}}$ Channel Opening on Tonic Currents at P2-4 versus P7-8}

When recorded without exogenous GABA, DIZ also exerted similar effects. Figure 3 depicts how the magnitudes of the tonic currents at both P2-4 and P7-11 were smaller than in the presence of exogenous GABA ( $p<0.05$; Figures $2 \mathrm{~B}$ and $3 \mathrm{~A}, \mathrm{~B})$. The level at P2 -4 was also significantly higher than that at P7-11 in controls (Figure 3B). Interestingly, we found that DIZ decreased the levels at $\mathrm{P} 2-4(p<0.05)$ and significantly increased them at $\mathrm{P} 7-11$ $(p<0.05)$. In contrast, 5-HD did not significantly alter levels at either P2-4 or P7-11 (two-way ANOVAs, $p>0.05$; Figure 3B).

\section{$\alpha 5-$ and $\delta$-Subunit-Containing $\mathrm{GAB}_{\mathrm{AA}}$ Rs Participate in Mediating Tonic Currents in the Presence of Exogenous GABA}

The $\alpha 5, \delta$-containing $\mathrm{GABA}_{\mathrm{A}}$ receptors are rich in rat cortical layer 5; in L655708, an inverse agonist of $\alpha 5$-containing $\mathrm{GABA}_{\mathrm{A}} \mathrm{Rs}$; and THIP, a selective agonist of $\delta$-containing $\mathrm{GABA}_{\mathrm{A}}$ Rs. We can record tonic current in the presence of THIP and/or L655708, which means that $\alpha 5$ and $\delta \mathrm{GABA}_{\mathrm{A}} \mathrm{R}$ take part in mediating tonic currents recorded in neonatal layer 5 neocortical pyramidal cells, and their contribution to tonic currents increases with development to some extent. This indicated that the expression of subunits $\alpha 5$ and $\delta$ and their influence on tonic currents were associated with rat age. THIP and L655708 increased $\Delta I_{\text {hold }}$, although the magnitude of tonic currents was small. We further analyzed $\Delta I_{\text {hold }}$ caused by L655798 and THIP. The results were as follows: $\Delta I_{\text {hold }}$ by $2.90 \pm 0.62 \mathrm{pA}$ and $4.50 \pm 1.03 \mathrm{pA}$ at P2 -4 , respectively; and by $3.98 \pm 0.76 \mathrm{pA}$ and $3.82 \pm 0.58 \mathrm{pA}$ at $\mathrm{P} 7-11$, respectively (Figure 4D). 
A

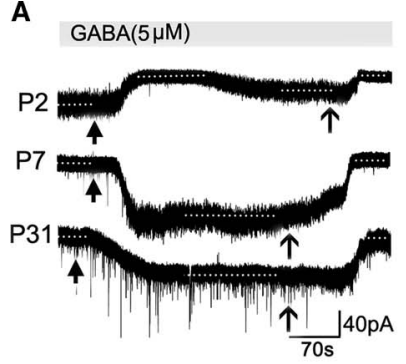

D

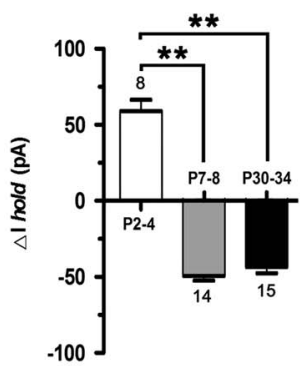

GABA+DIZ
B

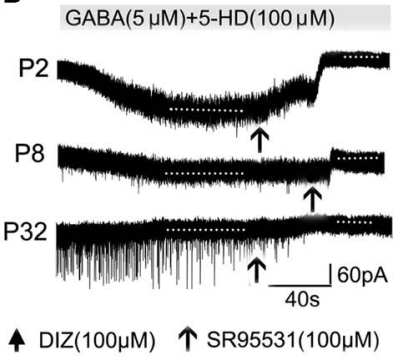

$\mathrm{E}$

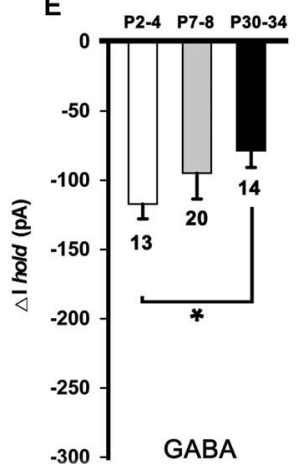

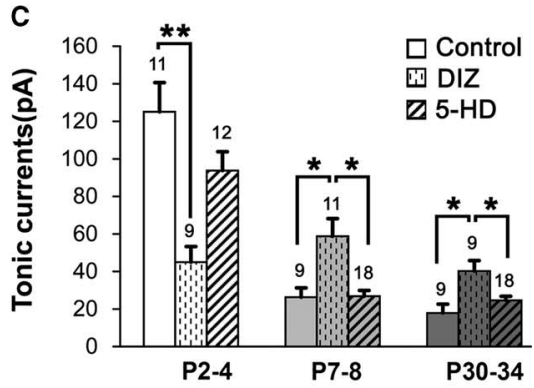

Figure 2: Opposing effects of $K_{A T P}$ channel opening on tonic currents at P2-4 versus P7-8 and P30-34 in the presence of exogenous GABA. $(A 1, A 2)$ Representative recording traces of the tonic currents at $P 2, P 7$, and $P 31$ with $D I Z$, an opener of mito $K_{A T P}$ channels $(A)$, and $5-H D$, an inhibitor of mitoK $K_{A T P}$ channels $(B)$. (C) Histograms show that DIZ inhibited the tonic currents at P2-4 and significantly enhanced tonic currents at both P7-8 and P30-34, compared to controls. However, treatment with 5-HD did not significantly change the tonic currents in the three age groups. Furthermore, DIZ caused an increase at P2-4 and decreases at P7-8 and P30-34 of the baseline changes $\left(\Delta I_{\text {hold }}\right)$, respectively $(D)$. Single application with $G A B A$ decreased $\triangle I_{\text {hold }}$ for all three age groups $(E)$. One-way ANOVA and LSD post-hoc test. ${ }^{*} p<0.05,{ }^{* *} p<0.001$. Mean \pm SEM.

\section{Opening $\mathrm{K}_{\mathrm{ATP}}$ Channels Enhances Tonic GABA Currents with Application of L655708 or THIP}

Opening of $\mathrm{K}_{\mathrm{ATP}}$ channels with DIZ affected tonic currents in the presence of L655708 or THIP. We found that DIZ enhanced tonic currents in the presence of L655708 at P7-11 (Figure 5A1, B). DIZ also significantly increased tonic currents in the presence of THIP at P2-4 and P7-11, respectively, and this effect was most obvious at P2-4 (Figure 5A2,C). Our results indicated that opening of $\mathrm{K}_{\mathrm{ATP}}$ channels with DIZ indeed mediates tonic currents.

\section{Discussion \\ Elevated Tonic GABA Currents in the Presence of High Levels of Exogenous GABA}

We found that the magnitude of tonic currents recorded after application of 5- $\mu \mathrm{M}$ exogenous GABA was higher than the tonic currents recorded without exogenous GABA at P2-4 and P7-11 (Figures 1A,B, and 3A,B). The magnitude recorded in the presence of $10-\mu \mathrm{M}$ exogenous GABA (P3: $195.98 \mathrm{pA}[n=2$ ]; P9: $37.25 \mathrm{pA}[n=3])$ was also higher than the magnitude recorded with $5-\mu \mathrm{M}$ exogenous GABA. Our finding that the tonic currents
A1

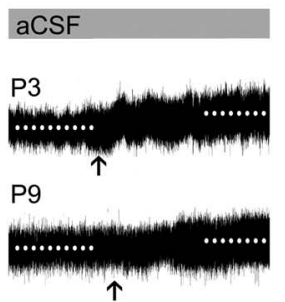

A2

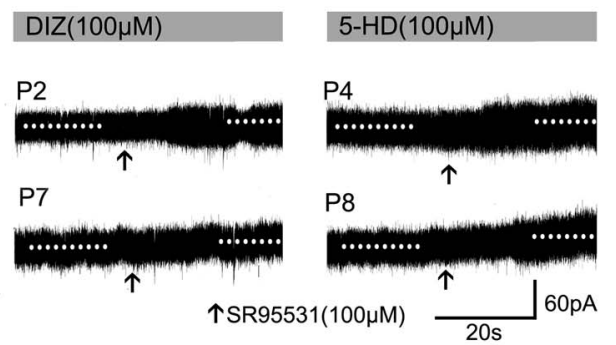

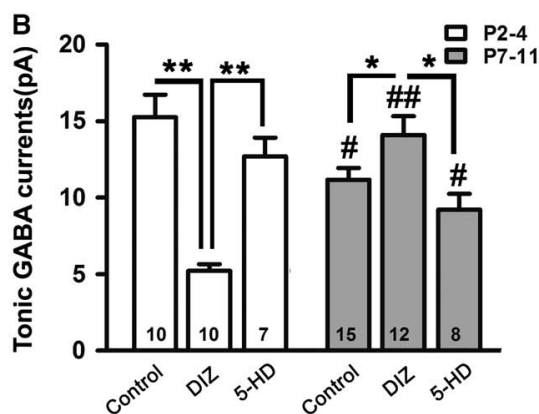

Figure 3: Opposing effects of $K_{A T P}$ channel opening on tonic currents at $P 2-4$ versus $P 7-8$ when recorded without exogenous application of GABA. (A1-A3) Representative recording traces of tonic currents with aCSF (A1), DIZ (A2), and 5-HD (A3). (B) Bar graph indicates that the magnitude of tonic currents at both P2-4 and P7-11 are smaller than that with exogenous GABA. The level at P2-4 was significantly higher than that at P7-11 in controls, and DIZ decreased the level at P2-4 and significantly increased it at P7-11. In contrast, 5-HD did not significantly regulate its levels at both P2-4 and P7-11. Unpaired t test. ${ }^{*} p<0.05,{ }^{* *} p<0.001,{ }_{p}^{\#}<0.05,{ }^{\#} p<0.001$ compared to P2-4 under the same conditions. Mean \pm SEM. 
A1

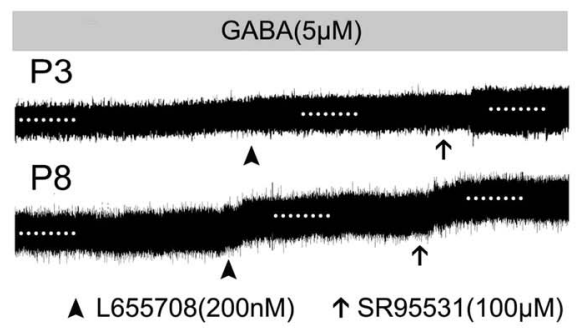

A2

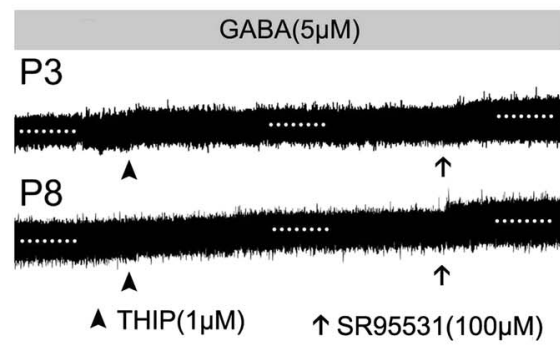

A3

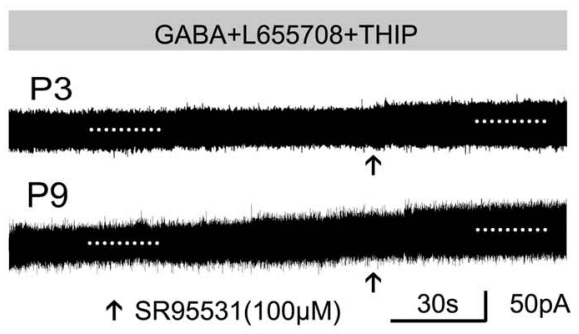

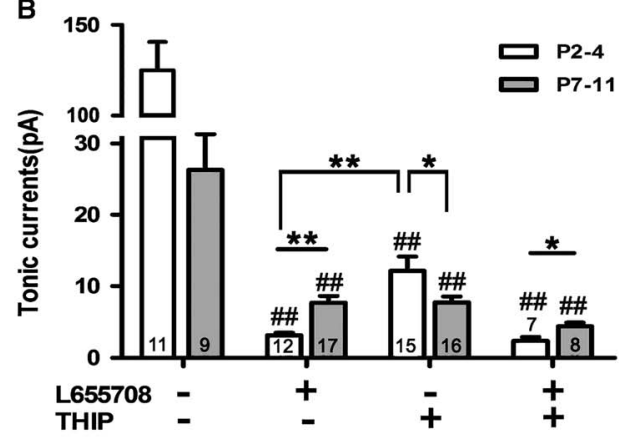

C

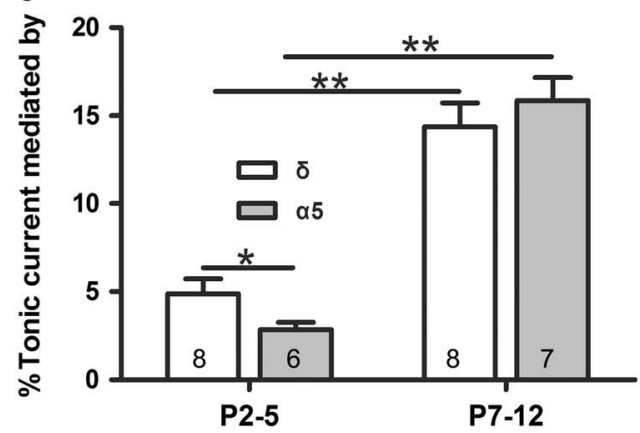

D

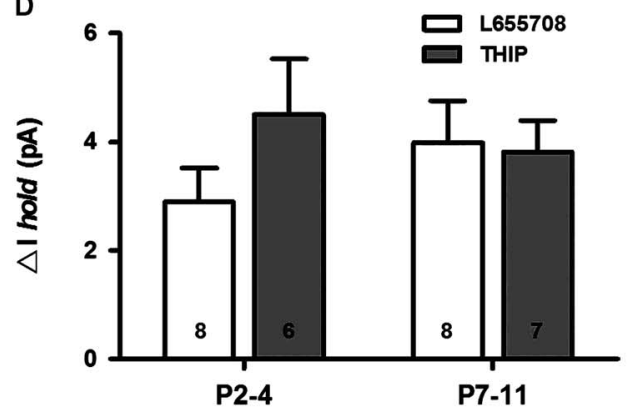

Figure 4: $\alpha 5$ - and $\delta$-subunit-containing $G A B A_{A} R$-mediated tonic GABA currents in the presence of exogenous GABA. (A1-A3) Representative recording traces of tonic currents with L655708, an inhibitor of $\alpha 5$-containing $G A B A_{A} R s$ (A1), THIP, an inhibitor of $\delta$-containing $G A B A_{A} R s$ (A2), and L655708/THIP (A3). (B,C) Bar graph shows that $\alpha 5$ and $\delta G A B A_{A} R$ take part in mediating tonic currents recorded in neonatal layer 5 neocortical pyramidal cells, and that their contribution to tonic currents increased with development. ${ }^{*} p<0.05,{ }^{*}{ }_{p}<0.001$. Mean \pm SEM. One-way ANOVAs with post-hoc (LSD) analysis. (C) Bar graph indicates that $\alpha 5$ and $\delta$ inhibitor increased $\Delta I_{\text {hold, }}$ although the magnitude of tonic current was small. Mean \pm SEM.

can be increased by elevated extracellular GABA concentrations implies that the $\mathrm{GABA}_{\mathrm{A}} \mathrm{Rs}$ involved are not saturated by the ambient GABA in vivo because we showed that only a small portion of the para-synaptic $\mathrm{GABA}_{\mathrm{A}} \mathrm{Rs}$ open at the same time, and this is an important feature of tonic currents in adult neurons. ${ }^{13}$ Another possibility is that the increased GABA alters the relative contribution of specific $\mathrm{GABA}_{\mathrm{A}}$ Rs to the tonic currents, as other subunit-containing $\mathrm{GABA}_{\mathrm{A}} \mathrm{R}$ populations may be recruited under conditions of increased ambient GABA. ${ }^{8}$

\section{Activation of $\mathrm{K}_{\mathrm{ATP}}$ Channel-Regulated Tonic Currents in the Presence or Absence of Exogenous GABA}

We found that DIZ exerts an opposite effect on the tonic currents recorded from cortical layer 5 pyramidal neurons during the first week versus the second week after birth; specifically, DIZ significantly decreased tonic currents at $\mathrm{P} 2-4$ but increased tonic currents at P7-10 (and also at P30-34). This regulation by DIZ might occur partially through $\mathrm{GABA}_{\mathrm{A}} \mathrm{Rs}$, and the ambient GABA concentration might be another key factor. Through the use of microdialysis techniques, investigators have demonstrated that $\mathrm{K}_{\mathrm{ATP}}$ channels can regulate ambient GABA levels, and that DIZ dramatically decreases GABA levels in the ventromedial hypothalamus with a concomitant onset of hypoglycaemia. ${ }^{14}$ In the absence of glucose, $\mathrm{K}_{\mathrm{ATP}}$ channel blockers enhance the release of GABA from rat hippocampal neurons. ${ }^{15}$ Although we detected DIZ-induced regulation of GABA release in the present study under relatively normal conditions and at certain levels of metabolic conditions in the aCSF, these metabolic factors may still be involved in the $\mathrm{K}_{\mathrm{ATP}}$ channel's effects on GABA concentrations. 
A1
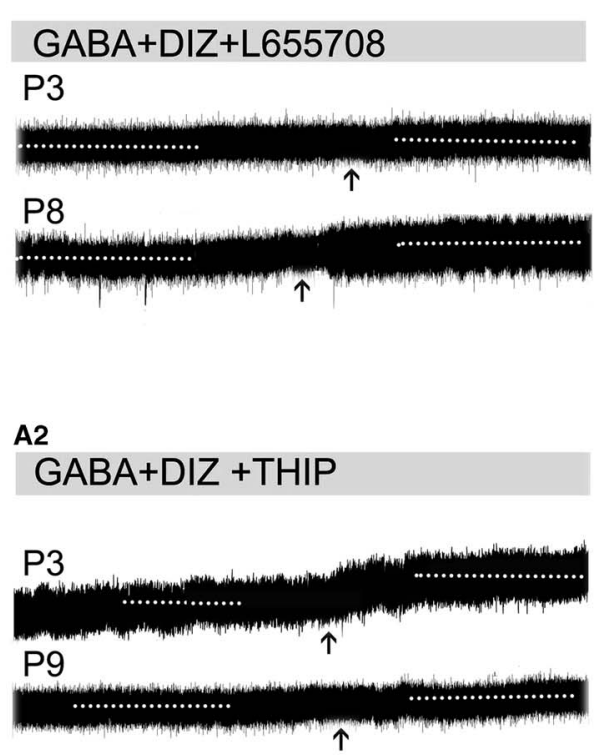

$\uparrow$ SR95531

20 s J30pA

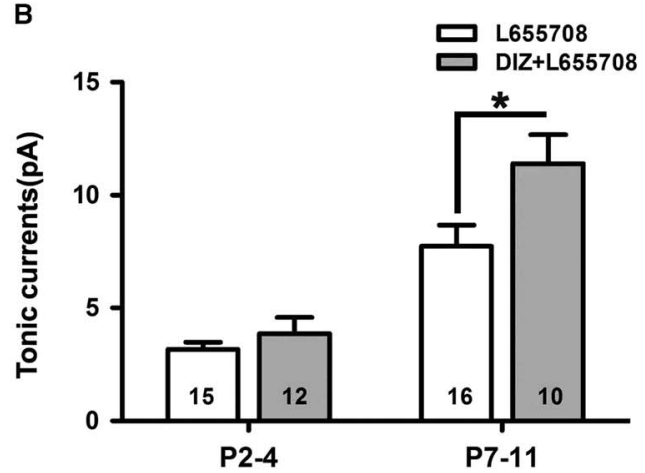

C

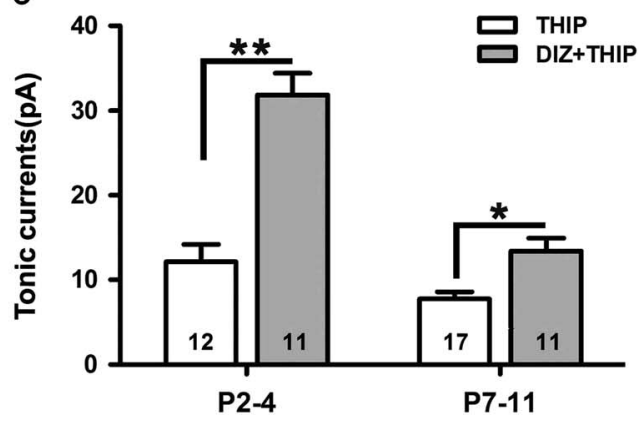

Figure 5: Opening of $K_{A T P}$ channels enhances tonic currents in the presence of L655708 or THIP. $(A 1, A 2)$ Representative recording traces of tonic currents under the conditions of mito $K_{A T P}$ channels activated by DIZ in the presence of L655708 (A1) and THIP (A2). (B) Bar graph shows that DIZ enhances tonic currents under the condition of $\alpha 5$ subunit- containing $G A B A_{A} R$ blockade at both P2-4 and P7-11, but significant enhancement could only been detected at P7-11. (C) Bar graph indicates that $D I Z$ significantly increases tonic currents under the conditions of $\delta$-containing $G A B A_{A} R$ blockade at P2-4 and P7-11, respectively, and this effect was obvious at P2-4. Unpaired t test. $p<0.05$, ** $p<0.001$. Mean \pm SEM.

Within the hippocampus and neocortex, GABA is considered to be excitatory in early development due to a relatively depolarized $\mathrm{Cl}^{-}$reversal potential. It is possible that this opposite effect of DIZ on the tonic currents from cortical layer 5 pyramidal neurons may relate to this dynamic change in the action of GABA from excitatory to inhibitory with development.

\section{Linkage of mitoK $\mathrm{K}_{\mathrm{ATP}}$ Channels to Alterations in Cellular Physiology}

MitoK $_{\mathrm{ATP}}$ channels are distinct pharmacological targets. When cardiac mitoK $\mathrm{K}_{\mathrm{ATP}}$ channels and $\mathrm{sK}_{\mathrm{ATP}}$ channels were studied under identical conditions, DIZ was shown to be a thousand times more potent in opening mito $\mathrm{K}_{\mathrm{ATP}}$ channels than $\mathrm{sK} \mathrm{K}_{\mathrm{ATP}}$ channels. Further, 5-HD was shown to inhibit mitoK $\mathrm{ATP}_{\mathrm{AT}}$ channels, but not $\mathrm{sK}_{\mathrm{ATP}}$ channels, ${ }^{6,16}$ implying that the primary actions of DIZ are on mitoK $\mathrm{ATP}_{\mathrm{AT}}$ channels. The fact that both DIZ and 5-HD failed to alter concentrations of nucleoside diphosphates and triphosphates when applied under normoxic conditions ${ }^{17}$ suggests that there must be other factors involved.

The functions of mitoK $\mathrm{K}_{\mathrm{ATP}}$ channels are closely related to the mitochondrial $\mathrm{K}^{+}$cycle. One distinct role played by the mitochondrial $\mathrm{K}^{+}$cycle is to regulate the production of mitochondrialreactive oxygen species for cell signalling. ${ }^{18}$ Our previous study showed that opening astrocytic mitoK $\mathrm{ATP}_{\mathrm{AT}}$ channels with DIZ causes cytosolic $\mathrm{K}^{+}$efflux through membrane gap junctions and pannexin channels, ${ }^{19}$ and this ultimately raises the extracellular
$\mathrm{K}^{+}$concentration, which can cause cell membrane hyperpolarization and reduce membrane excitability. ${ }^{20}$

\section{Effects of Activation of mitoK $\mathrm{ATP}_{\mathrm{A}}$ Channels on the Mean Baseline}

The regulation of the tonic currents by mitoK $\mathrm{K}_{\mathrm{ATP}}$ channel activation could be related to effects on baseline holding currents, which were up-regulated at P2-4 and down-regulated at both P7-8 and P30-34 after DIZ administration in the presence of exogenous GABA. This change in baseline holding currents $\left(\Delta I_{\text {hold }}\right)$ was negatively correlated with the magnitude of tonic currents under such conditions; however, this phenomenon was not observed without exogenous GABA, indicating that DIZinduced regulation of tonic currents is related to ambient GABA concentrations. GABA caused a potent down-regulation of $\Delta I_{\text {hold }}$ in the three age groups. Interestingly, activation of mitoK ${ }_{\mathrm{ATP}}$ channels reverses this GABA-induced down-regulation of $\Delta I_{\text {hold }}$ at P2-4, and diminishes the magnitude of $\Delta I_{\text {hold }}$ at P7-10 and P30-34 (Figure 2D,E). Activation of mitoK ${ }_{\mathrm{ATP}}$ channels with DIZ in the presence of exogenous GABA did affect baseline holding currents in the three age groups, and showed an opposite effect at P2-4 versus P7-10 and P30-34. This regulation by DIZ may be related to the dynamic changes in GABA from an excitatory to an inhibitory neurotransmitter with development. 


\section{Alpha-5, 8 -Containing GABA ${ }_{A}$ Rs Participate in Mediating Tonic Currents and Are Influenced by DIZ}

Tonic currents are mainly composed of $\alpha 5, \delta$-containing $\mathrm{GABA}_{\mathrm{A}} \mathrm{Rs}$ in most brain regions under normal physiological conditions, ${ }^{9}$ and polymerase chain reaction results confirm that the $\alpha 5$ and $\delta \mathrm{GABA}_{\mathrm{A}} \mathrm{Rs}$ subunits are rich in cortical layer $5 .{ }^{10} \mathrm{We}$ found that the $\alpha 5$ - and $\delta$-subunit-containing $\mathrm{GABA}_{\mathrm{A}} \mathrm{Rs}$ take part in mediating tonic currents from neonatal pyramidal cells of somatosensory cortical layer 5 , though the magnitude of the tonic current was small because research found that only a very small fraction of the available extrasynaptic $\mathrm{GABA}_{\mathrm{A}} \mathrm{Rs}$ maintain simultaneous opening in adult neurons ${ }^{20}$ indicating that a large number of receptors are heavily desensitized. ${ }^{9}$ There is no direct link between DIZ/mitoK $\mathrm{ATP}_{\text {and }}$ GABA $\mathrm{A}_{\mathrm{A}} \mathrm{Rs}$, but we found that DIZ can up-regulate tonic currents. We speculate that L655708 and THIP consumed $\alpha 5$ - and $\delta$-subunit-containing $\mathrm{GABA}_{\mathrm{A}} \mathrm{Rs}$, and other extrasynaptic $\mathrm{GABA}_{\mathrm{A}} \mathrm{Rs}$ became sensitive to the GABA that existed in the bath solution, while mitoK $\mathrm{K}_{\mathrm{ATP}}$ activated by DIZ regulated GABA release under relatively normal conditions. Therefore, DIZ enhanced tonic currents in the presence of THIP and/or L655708.

\section{Pathophysiological Implications}

Previous studies have suggested that DIZ can prevent the initial hyperexcitability produced by anoxia, ${ }^{21}$ while according to our previous research we deduced that the anticonvulsant action of mitoK $\mathrm{K}_{\text {ATP }}$ channels is achieved, at least in part, by enhancing astrocytic mitoK $\mathrm{K}_{\mathrm{ATP}}$ channel-regulated gap-junction coupling ${ }^{22}$ and electrical coupling ${ }^{19}$ between astrocytes, in addition to neuronal mitoK $_{\text {ATP }}$ channel-modulated excitability. The present study revealed a novel pharmacological profile of mitoK $_{\text {ATP }}$ channel activators as regulators of tonic GABA transmission, and our results may provide a new strategy for antiepileptic treatments.

\section{Conclusions}

Tonic currents from neocortical layer 5 pyramidal neurons in rats follow certain rules with development. To some extent, the amplitude of the current depends on extracellular GABA concentrations. This neonatal tonic current was partially mediated by the $\mathrm{GABA}_{\mathrm{A}} \mathrm{R} \alpha 5$ and, likely, $\delta$ subunits. Activation of $\mathrm{K}_{\mathrm{ATP}}$ channels, especially the mitoK $\mathrm{ATP}_{\text {TTP }}$ channels, with DIZ has an opposite effect on the tonic currents with development.

\section{ACKNOWLEDGMENTS}

This work was supported by the National Natural Science Foundation of China (30570644 and 81300975), the Natural Science Foundation of Zhejiang Province (R2090266), the Zhejiang Province Key Technology Innovation Team (2010R50049), the Zhejiang Provincial Qianjiang Talent Plan (2011R10040), the Key Laboratory of Medical Neurobiology of the Ministry of Health at Zhejiang University, the Key Laboratory of Reproductive Genetics (Zhejiang University), the Ministry of Education, and the Key Laboratory for Diagnosis and Therapy of Neonatal Diseases of Zhejiang Province.

\section{DISCLOSURES}

Dr. Li reports grants from the National Natural Science Foundation of China (81571263,81401071 and 81300975), the
Natural Science Foundation of Zhejiang Province (R2090266), the Zhejiang Province Key Technology Innovation Team (2010R50049), the Zhejiang Provincial Qianjiang Talent Plan (2011R10040), the Key Laboratory of Medical Neurobiology of the Ministry of Health at Zhejiang University, the Key Laboratory of Reproductive Genetics (Zhejiang University), the Ministry of Education, and the Key Laboratory for Diagnosis and Therapy of Neonatal Diseases of Zhejiang Province, during the conduct of the study.

Dr. Wang reports grants from the National Natural Science Foundation of China (81571263,81401071 and 81300975), the Natural Science Foundation of Zhejiang Province (R2090266), the Zhejiang Province Key Technology Innovation Team (2010R50049), the Zhejiang Provincial Qianjiang Talent Plan (2011R10040), the Key Laboratory of Medical Neurobiology of the Ministry of Health at Zhejiang University, the Key Laboratory of Reproductive Genetics (Zhejiang University), the Ministry of Education, and the Key Laboratory for Diagnosis and Therapy of Neonatal Diseases of Zhejiang Province, during the conduct of the study.

Dr. Yu reports grants from the National Natural Science Foundation of China (81571263,81401071 and 81300975), the Natural Science Foundation of Zhejiang Province (R2090266), the Zhejiang Province Key Technology Innovation Team (2010R50049), the Zhejiang Provincial Qianjiang Talent Plan (2011R10040), the Key Laboratory of Medical Neurobiology of the Ministry of Health at Zhejiang University, the Key Laboratory of Reproductive Genetics (Zhejiang University), the Ministry of Education, and the Key Laboratory for Diagnosis and Therapy of Neonatal Diseases of Zhejiang Province, during the conduct of the study.

Dr. Jiang reports grants from the National Natural Science Foundation of China (81571263,81401071 and 81300975), the Natural Science Foundation of Zhejiang Province (R2090266), the Zhejiang Province Key Technology Innovation Team (2010R50049), the Zhejiang Provincial Qianjiang Talent Plan (2011R10040), the Key Laboratory of Medical Neurobiology of the Ministry of Health at Zhejiang University, the Key Laboratory of Reproductive Genetics (Zhejiang University), the Ministry of Education, and the Key Laboratory for Diagnosis and Therapy of Neonatal Diseases of Zhejiang Province, during the conduct of the study.

\section{REFERENCES}

1. Bajgar R, Seetharaman S, Kowaltowski AJ, Garlid KD, Paucek P. Identification and properties of a novel intracellular (mitochondrial) ATP-sensitive potassium channel in brain. J Biol Chem. 2001;276(36):33369-74; Epub ahead of print Jul 5. Available at: http://www.jbc.org/content/276/36/33369.full.pdf.

2. Nichols CG. $\mathrm{K}_{\text {ATP }}$ channels as molecular sensors of cellular metabolism. Nature. 2006;440(7083):470-6.

3. Sargent CA, Sleph PG, Dzwonczyk S, Normandin D, Antonaccio MJ, Grover GJ. Cardioprotective effects of the cyanoguanidine potassium channel opener P-1075. J Cardiovasc Pharmacol. 1993;22(4): 564-570.

4. Xue J, Zhou D, Yao H, Haddad GG. Role of transporters and ion channels in neuronal injury under hypoxia. Am J Physiol Regul Integr Comp Physiol. 2008;294(2):R451-7; Epub ahead of print Oct 31, 2007. Available at: http://ajpregu.physiology.org/content/ 294/2/R451.

5. Seino S, Miki T. Physiological and pathophysiological roles of ATPsensitive $\mathrm{K}^{+}$channels. Prog Biophys Mol Biol. 2003;81(2):133-76.

6. Garlid KD, Paucek P, Yarov-Yarovoy V, et al. Cardioprotective effect of diazoxide and its interaction with mitochondrial 
ATP-sensitive $\mathrm{K}^{+}$channels: possible mechanism of cardioprotection. Circ Res. 1997;81(6):1072-82; Available at http://circres. ahajournals.org/content/81/6/1072.long.

7. Ulrich D. Differential arithmetic of shunting inhibition for voltage and spike rate in neocortical pyramidal cells. Eur J Neurosci. 2003;18(8):2159-65.

8. Semyanov A, Walker MC, Kullmann DM. GABA uptake regulates cortical excitability via cell type-specific tonic inhibition. Nat Neurosci. 2003;6(5):484-90.

9. Brickley SG, Mody I. Extrasynaptic GABA(A) receptors: their function in the CNS and implications for disease. Neuron. 2012;73(1):23-34; Available at https://www.ncbi.nlm.nih.gov/ pmc/articles/PMC3399243/.

10. Yamada J, Furukawa T, Ueno S, Yamamoto S, Fukuda A. Molecular basis for the GABAA receptor-mediated tonic inhibition in rat somatosensory cortex. Cereb Cortex. 2007;17(8):1782-7; Epub ahead of print Sep 22, 2006. Available at: https://academic.oup. com/cercor/article-lookup/doi/10.1093/cercor/bhl087.

11. Drasbek KR, Jensen K. THIP, a hypnotic and antinociceptive drug, enhances an extrasynaptic $\mathrm{GABA}_{\mathrm{A}}$ receptor-mediated conductance in mouse neocortex. Cereb Cortex. 2006;16(8):1134-41; Epub ahead of print Oct 12, 2005. Available at: https://academic. oup.com/cercor/article-lookup/doi/10.1093/cercor/bhj055.

12. Sebe JY, Looke-Stewart EC, Estrada RC, Baraban SC. Robust tonic GABA currents can inhibit cell firing in mouse newborn neocortical pyramidal cells. Eur J Neurosci. 2010;32(8):1310-8; Epub ahead of print Sep 16. Available at: https://www.ncbi.nlm.nih. gov/pmc/articles/PMC2956765/pdf/nihms220675.pdf.

13. Kasugai Y, Swinny JD, Roberts JD, Dalezios Y, Fukazawa Y, Sieghart W, Shigemoto R, Somogyi P. Quantitative localisation of synaptic and extrasynaptic GABAA receptor subunits on hippocampal pyramidal cells by freeze-fracture replica immunolabelling. European Journal of Neuroscience. 2010;32(11): 1868-88.

14. Chan O, Lawson M, Zhu W, Beverly JL, Sherwin RS. ATP-sensitive $\mathrm{K}^{+}$channels regulate the release of GABA in the ventromedial hypothalamus during hypoglycemia. Diabetes. 2007;56(4):1120-6;
Epub ahead of print Jan 24. Available at: http://diabetes.diabetes journals.org/content/56/4/1120.long.

15. Margaill I, Miquet JM, Doble A, Blanchard JC, Boireau A. $\mathrm{K}_{\text {ATP }}$ channels modulate GABA release in hippocampal slices in the absence of glucose. Fundam Clin Pharmacol. 1992;6(7):295-300.

16. Garlid KD, Paucek P, Yarov-Yarovoy V, Sun X, Schindler PA. The mitochondrial $\mathrm{K}_{\mathrm{ATP}}$ channel as a receptor for potassium channel openers. J Biol Chem. 1996;271(15):8796-9; Available at http:// www.jbc.org/content/271/15/8796.long.

17. Reinhardt R, Manaenko A, Guenther A, et al. Early biochemical and histological alterations in rat corticoencephalic cell cultures following metabolic damage and treatment with modulators of mitochondrial ATP-sensitive potassium channels. Neurochem Int. 2003;43(6):563-71.

18. Garlid KD, Dos Santos P, Xie ZJ, Costa AD, Paucek P. Mitochondrial potassium transport: the role of the mitochondrial ATP-sensitive $\mathrm{K}^{+}$ channel in cardiac function and cardioprotection. Biochim Biophys Acta. 2003;1606(1-3):1-21; Available at: http://www.sciencedirect. com/science/article/pii/S0005272803001099.

19. Wang JP, Li ZX, Feng M, et al. Opening of astrocytic mitochondrial ATP-sensitive potassium channels upregulates electrical coupling between hippocampal astrocytes in rate brain slices. PLoS One. 2013;8(2).

20. Kasugai Y, Swinny JD, Roberts JD, et al. Quantitative localisation of synaptic and extrasynaptic $\mathrm{GABA}_{\mathrm{A}}$ receptor subunits on hippocampal pyramidal cells by freeze-fracture replica immunolabelling. Eur J Neurosci. 2010;32(11):1868-88; Epub ahead of print Nov 14. Available at: https://www.ncbi.nlm.nih.gov/pmc/articles/PMC4487 817/pdf/emss-63834.pdf.

21. Mattia D, Nagao T, Rogawski MA, Avoli M. Potassium channel activators counteract anoxic hyperexcitability but not 4-aminopyridine-induced epileptiform activity in the rat hippocampal slice. Neuropharmacology. 1994;33(12):1515-22.

22. Jiang K, Wang J, Zhao $\mathrm{C}$, et al. Regulation of gap junctional communication by astrocytic mitochondrial $\mathrm{K}_{\mathrm{ATP}}$ channels following neurotoxin administration in in-vitro and in-vivo models. Neurosignals. 2011;19(2):63-74; Epub ahead of print Apr 7. 